\title{
Phenolic Substances of Brown Algae and Their Antioxidant Activity
}

\author{
I. D. Chkhikvishvili* and Z. M. Ramazanov** \\ * Institute of Plant Biochemistry, Academy of Sciences of Georgia, Tbilisi, 380059 Georgia \\ ** Institute of Applied Phycology, Gran Canaria University, Telde, Las Palmas, 35214 Spain
}

Received April 19, 1999

\begin{abstract}
The composition and content of phenolic substances were studied in 14 species of marine brown algae of the Canary Islands littoral (Spain). The highest content of phenolic substances was found in Cystoseira compressia and Sargassum furcatum. A high antioxidant activity was found in florotannin isolated from Cystoseira sp.
\end{abstract}

Phenolic substances are obligatory constituents of plants [1]. In brown and red marine algae, they are represented by floroglucine polymers [2-4] called florotannins similarly to condensed tannins [5]. Brown algae contain various florotannins, including fucolls (I), florethols (II), fucoflorethols, fuhalols (III), isofuhalols, as well as halogenated and sulfited florotannins (IV).

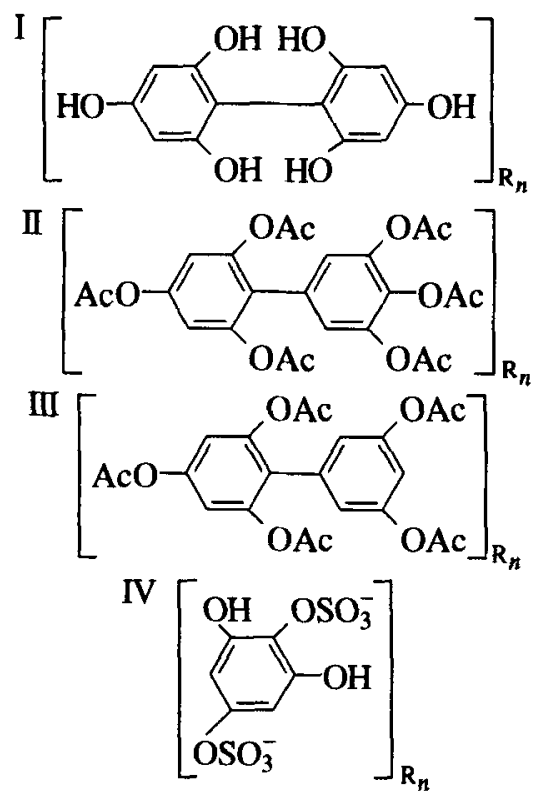

Florotannins were found in many Phaophyceae species, and these substances seem to protect algae against grass-feeding animals [2]. Florotannins are involved in detoxification of heavy metals due to complexing $[6,7]$. Antibacterial and fungicidal activities are also found in florotannins $[8,9]$.

This work was designed to study the composition and content of phenolic substances in brown algae abundant in the littoral of the Canary Islands, as well as the antioxidant activity of these substances.

\section{MATERIALS AND METHODS}

Brown algae were collected in the littoral of the Canary Islands (Spain).

Phenolic substances were extracted with $70 \%$ aqueous methanol. Total phenolic substances were determined by the Folin-Dennis method by development of blue color (absorption at $725 \mathrm{~nm}$ ) [10]. Floroglucine was used as the standard.

Isolation of florotannin from Cystoseira sp. Samples of the collected algae were placed into liquid nitrogen. The frozen material was flooded with methanol ( $1: 5$ by volume). Extraction was carried out with continuous stirring in the dark at $3^{\circ} \mathrm{C}$. Two days later, the mixture was filtered, and the extract was evaporated in vacuo to a small volume at a temperature no higher than $40^{\circ} \mathrm{C}$. The residue was supplemented with an equal volume of water, and methanol was removed in vacuo. To extract florotannin, the aqueous residue was treated three times with ethylacetate.

The resulting extract was dried above melted $\mathrm{Na}_{2} \mathrm{SO}_{4}$, filtered, and evaporated to a small volume.

Florotannin was precipitated from this extract by addition of five volumes of chloroform. The precipitate was dried in vacuo, and a powder of light cream color resulted.

Acetylation. A preparation $(0.5 \mathrm{~g})$ of florotannin extract obtained with ethylacetate was dissolved in a small amount of water-free pyridine, supplemented with a twofold volume of freshly distilled acetic anhydride, kept overnight at room temperature, then supplemented with a mixture of benzene-hexane $(1: 1 \mathrm{v} / \mathrm{v})$, mixed, and supplemented with chloroform until a milkcolor precipitate was produced. After settling, the sedi- 


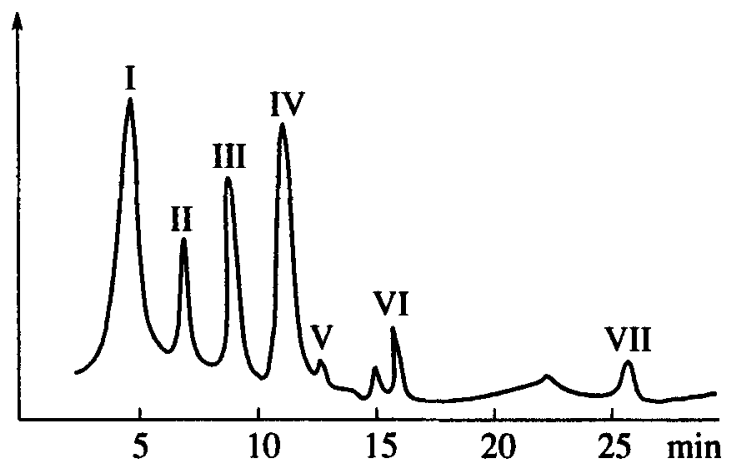

Fig. 1. Separation of acetylated derivatives of florotannins from Cystoseira sp. by gas-liquid chromatography. (I) Acetylated derivative of florotannin; (II-VII) unidentified.

ment of acetylated florotannin was filtered and used for chromatography.

Chromatography. Acetylated florotannin derivatives were separated by thin-layer chromatography (TLC) in silica gel (Merck, Germany) with the solvent system of chloroform-acetone $(92: 8 \mathrm{v} / \mathrm{v})$.

Acetylated florotannin derivatives were separated using a gas-liquid Shimadzu chromatograph GC-15A (Japan) with helium as the moving phase; capillary columns Supercowax 10 (SUP, USA) were used.

The isolated compound was identified using an authentic specimen of floroglucine (Sigma, USA), which was acetylated and compared by the $R_{f}$ value in

Content of phenolic compounds in brown algae of the $\mathrm{Ca}$ nary Islands

\begin{tabular}{l|l|c}
\hline \multicolumn{1}{c|}{ Alga } & $\begin{array}{c}\text { Place } \\
\text { of collection }\end{array}$ & $\begin{array}{c}\text { Phenolic } \\
\text { substances, } \\
\text { \% of dry weight }\end{array}$ \\
\hline Cystoseira foeniculaceae & Talliarti & 2.16 \\
Fucus spiralis & & 2.17 \\
Sargassum furcatum & & 2.97 \\
Padina pavonica & & 0.69 \\
Halopteris scoparia & & 0.16 \\
Dictyota ciliolata & 0.08 \\
Dictyopteris membranacea & & 0.09 \\
Cystoseira compressa & El Carbon & 4.83 \\
Sargassum desfontrainessi & & 1.68 \\
Lobophora variegata & & 1.20 \\
Stypopodium zonale & & 1.22 \\
Dictyota sp. 1 & & 0.03 \\
Dictyota sp. 2 & & 0.001 \\
Zonaria tonznefortii & Arinaga & 1.06 \\
\hline
\end{tabular}

a thin layer of silica gel (TLC) and by the retention time in gas-liquid chromatography (GLC).

The antioxidant activity of florotannin preparations was determined by using 2,2-diphenyl-1-picrylhydrazine (DPPH) as a source of free radicals. A sample of florotannin was dissolved in methanol $(1 \mathrm{mg} / \mathrm{ml})$ and added to DPPH solution [11]. To determine the antioxidant activity, a decrease in $D_{515}$ value was measured every $10 \mathrm{~s}$ until the end of the reaction.

\section{RESULTS AND DISCUSSION}

The contents of phenolic substances in brown algae of the Canary Islands are shown in the table. The richest in phenolic substances were brown algae as follows: Cystoseira foeniculacea (the Talliarti littoral), Labophora variegata and Stypopodium zonale (the El Cabron littoral). Dictyota spp. 1 and 2 and also Dictyota ciliolota had an insignificant amount of phenolic substances. Thus, the content of phenolic substances in brown algae of the Canary Islands littoral was lower than in tropical seas, where it is about $25 \%$ [12].

The preparation from Cystoseira sp. in ethylacetate acquired an intense red color in the presence of vanillin reagent; and, thus, it was identified as floroglucine.

Acetylated derivatives of the ethylacetylated preparation were separated into several constituents by TLC in silica gel, with chloroform-acetone mixture as the solvent. The elution was started with absolute chloroform, and the relative content of acetone was gradually increased $(95: 5,93: 7,90: 10 \mathrm{v} / \mathrm{v})$. As a result, seven constituents were isolated, one of which was identified as an acetylated derivative of floroglucine (Fig. 1, peak I). Acetylated florotannin from Cystoseira sp. was also separated by GLC into seven constituents (Fig. 1). Note that some authors [13] have found that brown algae contain only three constituents: floroglucine and its two dimers (bifuhanol and diflorethol).

Florotannin preparation from Cystoseira sp. had a higher antioxidant activity as compared to other antioxidants, e.g., floroglucine and picnogenol, a commercial preparation from pine bark (Fig. 2). However, the content of phenolic compounds in the preparation from Cystoseira sp. was lower than in picnogenol (58 and $80 \%$, respectively).

Preparations of phenolic substances are promising as antioxidants for prevention of malignant tumors and some other diseases $[14,15]$.

Thus, acetylated derivatives of florotannins were successfully separated by TLC and GLC. The highest content of florotannins is accumulated by brown algae Cystoseira compressia and Sargassum furcatum. By decrease in the relative content of free radicals gener- 
$D_{515}, \%$ from DPPH

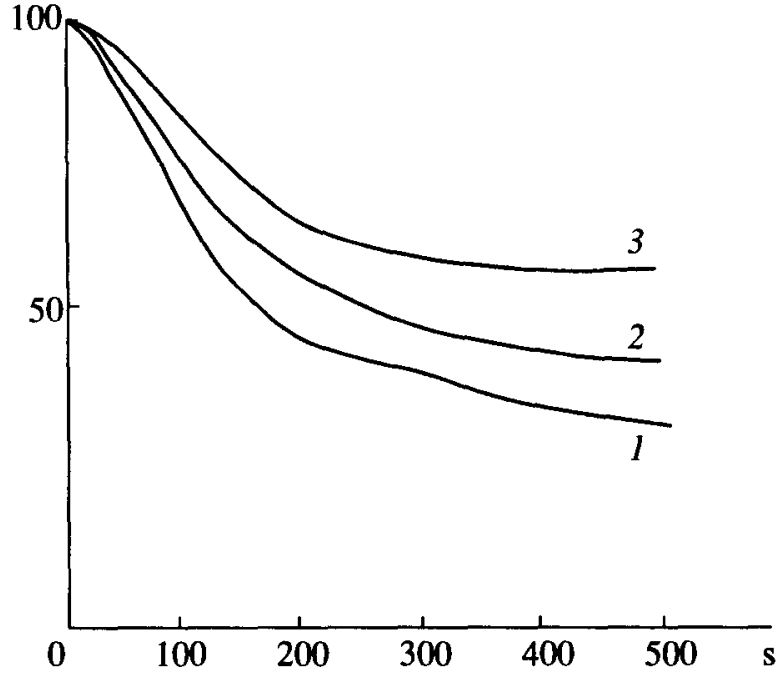

Fig. 2. Antioxidant activity of florotannin from Cystoseira sp. as compared to picnogenol. (l) Preparation from Cystoseira sp., (2) picnogenol, (3) floroglucine.

ated by 2,2-diphenyl-1-picrylhydrazine, a high antioxidant activity was found in the florotannin preparation from Cystoseira sp.

\section{ACKNOWLEDGMENTS}

We are grateful to Prof. M.N. Zaprometov (Institute of Plant Physiology, Russian Academy of Sciences) for discussion of the manuscript and helpful remarks.

\section{REFERENCES}

1. Zaprometov, M.N., Fenol'nye soedineniya (Phenolic Compounds), Moscow: Nauka, 1993, p. 4.

2. Ragan, M.A. and Glombitza, L.N., Prog. Phycol. Res., 1986, vol. 2, no. 4, pp. 130-241.

3. Ragan, M.A. and Craigie, J.S., Handbook of Phycological Methods, Hellebust, J.A., Ed., Cambridge: Cambridge Univ. Press, 1978, vol. 2, pp. 157-179.

4. Tatsuo, H., Marine Natural Products Phenolic Substances, London: Academic, 1981, pp. 93-145.

5. Waterman, P.G. and Mole, S., Analysis of Phenolic Plants Metabolites, Oxford: Academic, 1994, pp. 30-34.

6. Myklestad, S., Eide, I., and Melson, S., Exp. Environ. Pollut., 1988, vol. 16, no. 2, pp. 277-284.

7. Eide, I., Myklestad, S., and Melson, S., Environ. Pollut. Ser. A, 1980, vol. 23, no. 1, pp. 19-28.

8. Ragan, M.A., Can. J. Chem., 1985, vol. 63, no. 2 , pp. 294-303.

9. Fagerberg, W.R. and Dawes, C.J., Am. J. Bot., 1976, vol. 63, no. 1, pp. 110-119.

10. Swain, T. and Hillis, W.E., J. Sci. Food Agric., 1959, vol. 10, no. 1, pp. 63-68.

11. Brand-Williams, W., Cuvelikr, M.E., and Berset, C., Leben Wiss. Technol., 1985, vol. 28, no. 1, pp. 25-30.

12. Targett, N.M., Boettcher, A.A., Targett, T.E., and Vrolijk, N.H., Oncologia, 1995, vol. 103, no. 1, pp. 170179.

13. Glombitza, K.W., Roscnes, H.N., and Muller, D., Phytochemistry, 1975, vol. 14, no. 3, pp. 1115-1116.

14. Sukonlinskii, V.N., Vopr. Onkol., 1990, vol. 36, no. 2, pp. 138-144.

15. Smirnov, L.D. and Suskova, V.S., Khim-Farm. Zh., 1989 , vol. 23, no. 7, pp. 773-784. 